\title{
A polymer hybrid film based on poly(vinyl cinnamate) and poly(2-hydroxy ethyl methacrylate) for controlled flurbiprofen release
}

\author{
Mamoon Alokour ${ }^{1,2}$ [D $\cdot$ Elvan Yilmaz ${ }^{2}$
}

Received: 27 October 2020 / Accepted: 10 March 2021/ Published online: 19 March 2021

(c) The Polymer Society, Taipei 2021

\begin{abstract}
A crosslinked polymer hybrid film, ipn-poly(vinyl cinnamate-graft-2-hydroxy ethyl methacrylate)- $v$-poly(ethylene glycol dimethacrylate) was synthesized by UV initiation using poly(vinyl cinnamate) (polyVCi), 2-hydroxy ethyl methacrylate (HEMA) monomer and ethylene glycol dimethacrylate (EGDMA) crosslinker. Benzophenone $\left(\mathrm{Ph}_{2} \mathrm{CO}\right)$, was used as the photoinitiator. The synthesis was optimized by changing the concentration of HEMA, $\mathrm{Ph}_{2} \mathrm{CO}, \mathrm{EGDMA}$, and UV irradiation time. PolyVCi undergoes photocrosslinking by $2+2$ photocylo addition while the monomer/crosslinker couple, HEMA/ EGDMA, undergoes free radical polymerization and crosslinking to form EGDMA crosslinked polyHEMA. Hence, simultaneous interpenetrating polymer network (IPN) formation occurs. The IPN consists of dual network of photocrosslinked polyVCi and EGDMA crosslinked polyHEMA chains. Grafting of HEMA/EGDMA chains on the polyVCi backbone also occur during network formation. The chemical functionalities present in the polyVCi/polyHEMA/polyEGDMA IPN films obtained were characterized by FTIR and SEM analysis. The contact angle measurements show enhanced wettability of the IPN film compared to polyVCi surface. TGA analysis confirms thermal stability of the films. Swelling behavior of the films examined in water and in ethanol reveals the effects of the chemical natures of polyVCi and polyHEMA as well as that of crosslinking on the hydrophilicity of the film. The films were tested as drug release matrices using flurbiprofen. The drug was loaded into the film matrix during IPN formation under UV irradiation. PolyVCi/polyHEMA/polyEGDMA IPN proved to be a suitable release matrix for flurbiprofen demonstrating controlled release behavior and zero-order release kinetics. The release mechanism was confirmed by its Ritger-Peppas " $n$ " value (1.00 to 1.42), which indicates super case II release.
\end{abstract}

Keywords Photoinitiation $\cdot$ Poly (vinyl cinnamate) $\cdot$ HEMA $\cdot$ IPN $\cdot$ Flurbiprofen $\cdot$ Controlled release

\section{Introduction}

Nowadays, controlled drug release is receiving increasing attention due to the need for effective and safer drug formulations with reduced side effects. Unlike conventional drug delivery formulations, controlled drug delivery systems release the drug into the desired biological fluid at a slower and constant rate [1]. In such systems, the drug is generally

Mamoon Alokour

malokour@gmail.com

1 Department of Basic Science, Huson University College, Al-Balqa Applied University, Irbid, Jordan

2 Department of Chemistry, Faculty of Arts and Sciences, Eastern Mediterranean University, via Mersin 10, Famagusta, North Cyprus, Turkey entrapped or encapsulated within a polymer matrix. These systems target at controlling and sustaining the distribution of drugs to achieve optimal therapeutic efficiency [2]. Furthermore, designed drug release profiles improve the specific action of the drug at the required site and when needed. One example to designed drug delivery is pulsatile drug delivery systems, which are developed to deliver the drug according to circadian behavior of diseases. In other words, these systems will deliver drug at a certain time when the disease shows its most morbid and mortal state within a circadian cycle, $24 \mathrm{~h}$. The product exhibits a sigmoidal drug release profile with no release known as lag time followed by a rapid and complete drug release. Thus, the drug can be delivered at the correct time, in the correct amount and at the right site of action using this approach [3].

Chemical, physical and biological processes affect the rate of drug release from the dosage form. The properties of 
the drug such as polarity and solubility, type of the polymer and binding agents, preparation methods, and the administration route are important parameters that govern these processes [4]. Diffusion of active and inactive part of the dosage form, hydration of the dosage form, polymer swelling and degradation, $\mathrm{pH}$ changes, drug degradation, are some elements of the chemical and physical processes involved in drug release kinetics. Simultaneous occurrence of these elements complicates the design of the drug formulation. Usually, one of these processes occurs slower than others and determines the overall rate of drug release. Various mathematical models are available to follow the drug release kinetics from matrix systems. Most commonly studied models are zero-order, first-order, Higuchi and Korssmayer-Peppas models.

Each model is characterized by the corresponding equation given below [5]:

Zero order model:

$Q_{t}=Q_{0}+K_{0} t$

where $\mathrm{Q}_{\mathrm{t}}$ is the amount of drug dissolved in time $t, \mathrm{Q}_{\mathrm{o}}$ is the initial amount of drug in solution, and $\mathrm{K}_{\mathrm{o}}$ is the rate constant of the release.

First order model:

$\log C=\log C_{0}-\frac{K t}{2.303}$

where $\mathrm{C}_{\mathrm{o}}$ is the initial concentration of drug, and $\mathrm{K}$ is first order release constant $t$ is time.

Higuchi model:

$Q=K_{H} t^{1} / 2$

where $\mathrm{Q}$ is the amount of drug released in time t per unit area, $K_{H}$ is Higuchi dissolution constant.

Korssmayer-Peppas model:

$\frac{M_{t}}{M_{\infty}}=K t^{n}$

where $M_{t} / M_{\infty}$ is a fraction of drug released at time $t, k$ is the release rate constant, and $\mathrm{n}$ is the release exponent.

An Interpenetrating Polymer Network (IPN) is a combination of two or more crosslinked polymers of different characteristics. It is synthesized when one polymer network is formed in the presence of the other either sequentially or simultaneously [6]. IPN's are useful as controlled release matrices as two polymer components of different nature may exist together forming a suitable medium to trigger drug release under different conditions. Some examples of IPN's with controlled drug release in the literature are as follows: The release behavior of bovine serum albumin (BSA) from silk sericin/poly(methacrylic acid), and silk sericin/
poly(N-isopropylacrylamide) IPN hydrogels [7]. A polyacrylamide grafted carrageenan and sodium alginate IPN was synthesized and represented a $\mathrm{pH}$ - responsive hydrogel used for targeting ketoprofen to the intestines [8]. Encapsulation and controlled release of diclofenac sodium was achieved in a smart macroporus IPN hydrogel that was synthesized sequentially by forming one network of poly $(\mathrm{N}, \mathrm{N}-$ dimethylaminoethyl methacrylate) crosslinked with $\mathrm{N}, \mathrm{N}^{\prime}$ methylenebisacrylamide (BAAm) at $-18^{\circ} \mathrm{C}$, followed by the other network of polyacrylamide crosslinked with BAAm [9].

In this study, polyVCi/polyHEMA IPN films were synthesized and tested for loading and release of the nonsteroidal anti-inflammatory drug (NSAID) flurbiprofen. The study presented here forms a simple, chemical model system composed of the polymeric matrix and the drug only, which may serve as a basis for further development of advanced drug formulations. Flurbiprofen is used during eye surgery and for the treatment of rheumatoid arthritis, ankylosing spondylitis, and degenerative joint disease for the reduction of pain, fever and inflammation [10]. When administered orally, flurbiprofen, as many NSAIDs, is absorbed from the upper gastrointestinal tract and causes gastric irritation [11]. Flurbiprofen use may cause other discomforting side effects in addition to stomach and intestinal disorders. Some of these are dizziness, drowsiness or allergic reactions such as itching and skin rush. Patients with rheumatoid arthritis that is characterized by joint pain and functional disability symptoms experience the symptoms of the disease most severely during early morning hours. The discomfort is experienced for long periods of time that pushes the tolerance limits of the patients. Hence, designing a time-controlled drug delivery system which could supply the therapeutic drug dosage at predetermined time intervals in a pulsatile manner is anticipated to improve patience compliance to the drug considerably as this would allow less frequent drug administration with reduced side effects. The polyVCi/polyHEMA/ polyEGDMA IPN films used in this study proved to fulfill this aim demonstrating controlled flurbiprofen release with lag time behavior.

The IPN polymer matrix synthesized is composed of polyVCi crosslinked network formed by $2+2$ photocylo addition under UV irradiation and polyHEMA crosslinked with EGDMA. Both networks were formed at the same time and under the same conditions. The hybrid polymer gel system composed of a dual network of photocrosslinked polyVCi and EGDMA crosslinked polyHEMA has not been reported in the literature before and is denoted as ipnpoly(vinyl cinnamate-graft-2-hydroxy ethyl methacrylate)$v$-poly(ethylene glycol dimethacrylate). Investigation of the physicochemical properties of the products proved achievement of a compromise between the more hydrophilic nature of polyHEMA and the hydrophobic nature of 
poly VCi polymer. The first component of the system, vinyl cinnamate (VCi), and especially its copolymers are well known for their photo responsive behavior including photo initiated polymerization, photo crosslinking [12], and light induced bending of its gels [13]. Cinnamoyl groups undergo $2+2$ photocylo addition to form crosslinked gels under UV light. Photo responsive hydrogels/nanogels of polyVCi can undergo UV induced bending or volume transition [14], which may find use in phototherapy, as drug carriers, or in medical imaging in addition to application in optoelectronics. PolyVCi and its copolymers with hydrophilic polymers can form micelles in solution and molecular arrangement leading to liquid crystal behavior [15]. Studies on either homopolymerization $[16,17]$ or copolymerization of $\mathrm{VCi}$ or on its blends and composites are scarce in the literature. Various poly(vinylalcohol-co-vinylcinnamate) derivatives including poly(vinylalcohol-co-vinylcinnamate), poly(vinylalcohol-co-vinyl-4-methoxycinnamate), poly(vinylalcohol-co-vinyl-2,4-di methoxy cinnamate) and poly(vinylalcohol-co-vinyl-2,4,5-trimethoxycinnamate) were synthesized by grafting poly(vinylalcohol) with appropriate cinnamoyl groups. Amphiphilic block or graft copolymers containing hydrophilic and hydrophobic segments have the ability of micelle formation by self-assembly in selective solvents [18]. Many blends and composites of polyVCi had been reported in the literature [19-21]. Poly(2-hydroxy ethyl methacrylate) (polyHEMA), on the other hand, has been proven to be a useful polymer for applications in the biomedical field since it was first synthesized in 1960. These applications include the use of polyHEMA in the fields of contact lenses, artificial corneas and skins, drug delivery, and degradable scaffolds for tissue engineering [22]. PolyHEMA hydrogels are versatile materials due to their non-toxicity, biocompatibility, and thermal stability [23].

Herein, optimum synthesis conditions for simultaneous IPN formation between poly VCi and polyHEMA is reported. The products have been characterized with respect to their chemical structures, chemical compositions, and physical properties such as surface morphology and thermal properties in addition to their swelling kinetics. The swelling characteristics and the contact angle measurements demonstrated modified hydrophilicity/hydrophobicity of the IPN formed with respect to individual polyVCi and polyHEMA. FTIR gave evidence with respect to the chemical structure of the products. TGA confirmed thermal stability up to $300{ }^{\circ} \mathrm{C}$, and SEM analysis enlighten the morphology. The product films proved to be suitable loading and release systems for flurbiprofen providing controlled drug release behavior. The synthesized polymeric release matrix is novel and exemplifies a hybrid polymeric system composed of polymers with hydrophilic/hydrophobic nature and suitable morphology giving rise to controlled release behavior for flurbiprofen with a two-step release profile separated by a lag time mimicking pulsatile release behavior.

\section{Materials and methods}

\section{Materials}

HEMA (Aldrich), and EGDMA (Aldrich) were cleaned from inhibitor by passing through inhibitor removal column (Aldrich). Flurbiprofen was provided by Pharma Mondial, North Cyprus. PolyVCi (Aldrich) was purified before use as described below. Benzophenone (Aldrich), chloroform (Aldrich), ethanol (Aldrich), methanol (Aldrich), tetrahydrofuran (THF) (Aldrich), and n-hexane (Aldrich) were used as received.

\section{Purification of polyVCi}

PolyVCi was cleaned from any poly(vinyl alcohol) impurity as follows: $0.5 \mathrm{~g}$ of polyVCi (Aldrich) was dissolved in $10.0 \mathrm{~mL}$ of chloroform. The solution was refluxed at $50{ }^{\circ} \mathrm{C}$ in an oil bath for $24 \mathrm{~h}$. Then the flask was cooled down, and $30.0 \mathrm{~mL}$ of $\mathrm{n}$-hexane was added to precipitate poly $\mathrm{VCi}$. The suspension was stirred overnight, filtered and dried at $60{ }^{\circ} \mathrm{C}$.

\section{IPN synthesis}

Purified PolyVCi was dissolved in THF to obtain a $5.0 \mathrm{~g} / \mathrm{L}$ solution. Then different amounts of HEMA monomer (20.6, 41.2, 82.5, $123.8 \mathrm{mM})$, the crosslinker EGDMA (13.2, 26.5, 52.9 mM), and the photoinitiator $\left(\mathrm{Ph}_{2} \mathrm{CO}\right),(6.86$, $13.7,27.4 \mathrm{mM}$ ), were added to the polymerization solution, closed, and connected to $\mathrm{N}_{2}$ gas bubbling system at room temperature for $20 \mathrm{~min}$. The values given in parentheses are the concentrations of each species, namely HEMA, EGDMA and $\mathrm{Ph}_{2} \mathrm{CO}$ in the initial polymerization medium. The reaction was carried out at different time intervals. PolyVCi film was prepared for comparison of physicochemical properties with those of the IPN films. The reaction conditions are shown in Table 1.

The homogeneous solutions $(20 \mathrm{~mL})$ were transferred into glass petri dishes and exposed to UV-irradiation using a Luzchem photoreactor LZC $4 \mathrm{~V}$ equipped with 6 top and 8 side UVA lamps of $350 \mathrm{~nm}$ wavelength and $7670 \mu \mathrm{W} . \mathrm{cm}^{-2}$ power. All samples were placed $15.0 \mathrm{~cm}$ distance from the lamps. Film samples were obtained after UV irradiation. The samples were taken from the chamber at given time intervals, soaked in ethanol for 2 days during which ethanol was refreshed regularly every $6 \mathrm{~h}$. Then, the films were dried at room temperature, to constant weight. The films 
Table 1 Synthesis conditions and Yield\% values for poly VCi/ polyHEMA/polyEGDMA IPN Films

\begin{tabular}{llclllc}
\hline Sample & $\begin{array}{l}\text { PolyVCi } \\
(\mathrm{g} / \mathrm{L})\end{array}$ & $\begin{array}{l}\text { HEMA } \\
(\mathrm{mM})\end{array}$ & $\begin{array}{l}\mathrm{Ph}_{2} \mathrm{CO} \\
(\mathrm{mM})\end{array}$ & $\begin{array}{l}\text { EGDMA } \\
(\mathrm{mM})\end{array}$ & $\begin{array}{l}\text { Time } \\
(\mathrm{h})\end{array}$ & Yield\% \\
\hline PolyVCi & 5.0 & - & 13.7 & - & 4 & - \\
M & 5.0 & 41.2 & 13.7 & - & 4 & 67.6 \\
$\mathrm{~A}$ & 5.0 & 41.2 & 6.86 & 26.5 & 4 & 49.4 \\
$\mathrm{~B}$ & 5.0 & 41.2 & 13.7 & 26.5 & 4 & 67.9 \\
$\mathrm{C}$ & 5.0 & 41.2 & 27.4 & 26.5 & 4 & 60.9 \\
$\mathrm{D}$ & 5.0 & 41.2 & 13.7 & 13.2 & 4 & 80.9 \\
$\mathrm{E}$ & 5.0 & 41.2 & 13.7 & 52.9 & 4 & 46.8 \\
$\mathrm{~F}$ & 5.0 & 20.6 & 13.7 & 26.5 & 4 & 81.6 \\
$\mathrm{G}$ & 5.0 & 82.5 & 13.7 & 26.5 & 4 & 65.7 \\
$\mathrm{Y}$ & 5.0 & 123.8 & 13.7 & 26.5 & 4 & 33.7 \\
$\mathrm{H}$ & 5.0 & 41.2 & 13.7 & 26.5 & 8 & 70.2 \\
$\mathrm{I}$ & 5.0 & 41.2 & 13.7 & 26.5 & 12 & 84.3 \\
$\mathrm{Z}$ & 5.0 & 41.2 & 13.7 & 26.5 & 16 & 54.2 \\
\hline
\end{tabular}

$\%$ Swelling Degree $=\frac{\mathrm{W}_{s}-\mathrm{W}_{d}}{\mathrm{~W}_{d}} \times 100 \%$

product yield was calculated according to Eq. (5).

Yield $\%=\frac{\mathrm{w}_{\mathrm{p}}}{\mathrm{w}_{\text {PolyVCi}}+\mathrm{w}_{\text {HEMA }}+\mathrm{w}_{\text {EGDMA }}} \times 100 \%$

where: $w_{\mathrm{p}}, \mathrm{w}_{\text {HEMA }}$ andw $\mathrm{w}_{\text {EGMMA }}$ stand for the weight of the product, initial weight of poly VCi, initial weight of HEMA and initial weight of EGDMA respectively, except for sample $\mathrm{M}$, in which no EGDMA was added.

\section{Gel content}

The gel content of the samples represented in Table 1 as $\mathrm{M}$, $\mathrm{B}, \mathrm{D}, \mathrm{E}$, and $\mathrm{H}$ films was measured by placing them into ethanol solvent for $48 \mathrm{~h}$ to ensure dissolution of all unreacted and/or soluble components. They were then dried at $50{ }^{\circ} \mathrm{C}$ for about $12 \mathrm{~h}$ to constant weight. The gel percent was calculated by using Eq. (6) given below.

Gel $\%=\frac{\mathrm{Wd}}{\mathrm{Wi}} \times 100 \%$

where: Wd is the weight of dried insoluble film and $\mathrm{Wi}$ is the initial weight of dried sample.

\section{Swelling behavior}

Known masses of films were placed in water and in ethanol. The weight of the swollen sample was measured at several time intervals after excess surface water or ethanol was removed. The procedure was repeated until there was no further weight increase. The swelling percent was calculated in terms of the amount of absorbed water or ethanol by using Eq. (7) given below. The results reported are average values of three measurements for each sample. where: $\mathrm{W}_{d}$ is the initial weight of dried film, and $\mathrm{W}_{s}$ is the final weight of the swollen film after a certain period of time.

\section{Flurbiprofen loading}

PolyVCi was dissolved in THF to obtain a $5.0 \mathrm{~g} / \mathrm{L}$ solution. Then a $41.2 \mathrm{mM}$ of HEMA monomer, $26.5 \mathrm{mM}$ of EGDMA, $13.7 \mathrm{mM}$ of $\mathrm{Ph}_{2} \mathrm{CO}$, and $\mathrm{FB}$ (20.5 or $10.25 \mathrm{mM}$ ) were added to the polymerization solution and closed, and connected to $\mathrm{N}_{2}$ gas bubbling at room temperature for $20 \mathrm{~min}$.. The homogeneous solutions $(20 \mathrm{~mL})$ were transferred into glass petri dishes and exposed to UV irradiation using a Luzchem photoreactor LZC $4 \mathrm{~V}$ equipped with 6 top and 8 side UVA lamps of $350 \mathrm{~nm}$ wavelength and $7670 \mu \mathrm{W} . \mathrm{cm}-2$ power. placed $15.0 \mathrm{~cm}$ distance from the lamps. Loaded films were obtained after UV irradiation, washed with ethanol several times, and dried at room temperature. The obtained films were labeled as $\mathrm{FB}_{1}$ and $\mathrm{FB}_{2}$ according to the initial concentration of the added drug; $\mathrm{FB}_{1}$ stands for $10.25 \mathrm{mM}$ of the drug, and when the initial concentration of drug is $20.5 \mathrm{mM}$ the film obtained is labeled as $\mathrm{FB}_{2}$.

Loaded films $\left(\mathrm{FB}_{1}\right.$ and $\left.\mathrm{FB}_{2}\right)$ were soaked in $100-\mathrm{mL}$ of ethanol at room temperature. Aliquot volume of $1.0 \mathrm{~mL}$ of solution was drawn from the release medium at several given time intervals, and was measured using a (UV_Win 5.0, Bejjing, T80+) UV/vis spectrometer at $249 \mathrm{~nm}$. Three repeated measurements were performed each time for data validation. After each draw, the release medium was The reaction was carried out for $8 \mathrm{~h}$. Both samples were

\section{Flurbiprofen release}


refreshed with pure ethanol to maintain a constant $100 \mathrm{~mL}$ of total solution volume during the experiment. Additional dilution was made on the drawn solution as needed, depending on the concentration of the drawn solution at the time of measurement. UV absorbance for each measured solution was then converted to flurbiprofen concentration using the best fit linear equation $\left(y=0.0716 x+0.0846, R^{2}=0.9914\right)$. Consequently, the amount of drug presence in the stock solution was calculated. Drug release profile was typically performed continuously with the last data point collected at $48 \mathrm{~h}$. The cumulative release $\%$ was calculated according to Eq. (8) $[10,24]$

Cumulative release $=\frac{\mathrm{M}_{\mathrm{T}}}{\mathrm{M}_{\infty}} \times 100 \%$

where $\mathrm{M}_{\mathrm{T}}$ is the amount of drug released from loaded films $\left(\mathrm{FB}_{1}, \mathrm{FB}_{2}\right)$ at time $\mathrm{t}$, and $\mathrm{M}_{\infty}$ is the amount of drug released from the loaded films at time infinity taken as $48 \mathrm{~h}$.

\section{Characterization techniques}

\section{FTIR-ATR analysis}

FTIR-ATR analysis of the films was made by using PerkinElmer Spectrum Two FTIR-ATR spectrometer.

\section{Thermal analysis}

Thermal Gravimetric Analysis (TGA) of the films was made using Perkin Elmer Diamond Differential Calorimeter and Perkin Elmer Pyris 1 under nitrogen atmosphere at $10{ }^{\circ} \mathrm{C} /$ min heating rate in Central Laboratory of Middle East Technical University, Ankara.

\section{Scanning electron micrographs (SEM)}

Scanning Electron micrographs (SEM) of the films were taken in Central Laboratory of Middle East Technical University, Ankara using Quanta 400F field emission scanning electron microscope using $\mathrm{Au}-\mathrm{Pd}$ coating.

\section{Size exclusion chromatography (SEC)}

The original polyVCi sample as provided by the producer and purified polyVCi were characterized by GPC in Middle East Technical University Central Laboratory using MalvernOmniSEC instrument. The solvent was THF and the flow rate was set as $1 \mathrm{~mL} / \mathrm{min}$.

\section{Contact angle}

Optical contact angle measurements on the films were made using Attension Theta goniometer in in Central Laboratory of Middle East Technical University, Ankara, Turkey.

\section{Results and discussion}

\section{Synthesis of ipn-poly(vinyl \\ cinnamate-graft-2-hydroxy ethyl methacrylate)-v-poly(ethylene glycol dimethacrylate) IPN films}

PolyVCi (Aldrich) was employed in IPN formation after purification as described above. The sample was found to have number average molecular weight of $9.20 \times 10^{4} \mathrm{~g} / \mathrm{mol}$ and weight average molecular weight of $1.74 \times 10^{5}$ by SEC analysis. IPN formation was carried out by photoinitiation at $350 \mathrm{~nm}$ by simultaneous photocrosslinking of poly VCi polymer backbone and formation of EGDMA crosslinked polyHEMA. The samples isolated after ethanol treatment are crosslinked gels. The synthesis route and a schematic representation of the crosslinked hybrid system formed are given in Fig. 1. This is a simultaneous IPN formation system, which is composed of three elements: (1) photocrosslinking of polyVCi chains via $[2+2]$ cycloaddition mechanism, (2) formation of polyHEMA by free radical polymerization of HEMA and crosslinking of polyHEMA in the presence of EGDMA crosslinker (3) possible photoinitiated grafting of polyHEMA and polyEGDMA from polyVCi chains via active centers that are created on the polyVCi backbone. Altogether these entities form the IPN gel. A schematic representation of the IPN gel formed is given in Fig. 1.

\section{Optimization of IPN synthesis conditions}

The IPN synthesis conditions were optimized with respect to initiator concentration, monomer and crosslinker concentrations and with respect to time. The synthesis conditions and the Yield \% values are shown in Table 1. The concentration of poly VCi solution was set as $5.0 \mathrm{~g} / \mathrm{L}$ in all experiments. A blank sample of photocrosslinked polyVCi film (poly VCi) was prepared to establish any mass changes during photocrosslinking. No loss or gain in mass was observed after photocrosslinking of poly VCi.

Studying the effect of $\mathrm{Ph}_{2} \mathrm{CO}$ concentration on the Yield \%, Fig. 2a, revealed that increasing concentration of $\mathrm{Ph}_{2} \mathrm{CO}$ from $6.86 \mathrm{mM}$ to $13.7 \mathrm{mM}$, results in an increase in Yield $\%$ value from $49.4 \%$ to $67.9 \%$, due to higher number of active sites created in the reaction medium hence higher grafting possibility of polyHEMA onto the polyVCi backbone together with more polyHEMA chains initiated in 

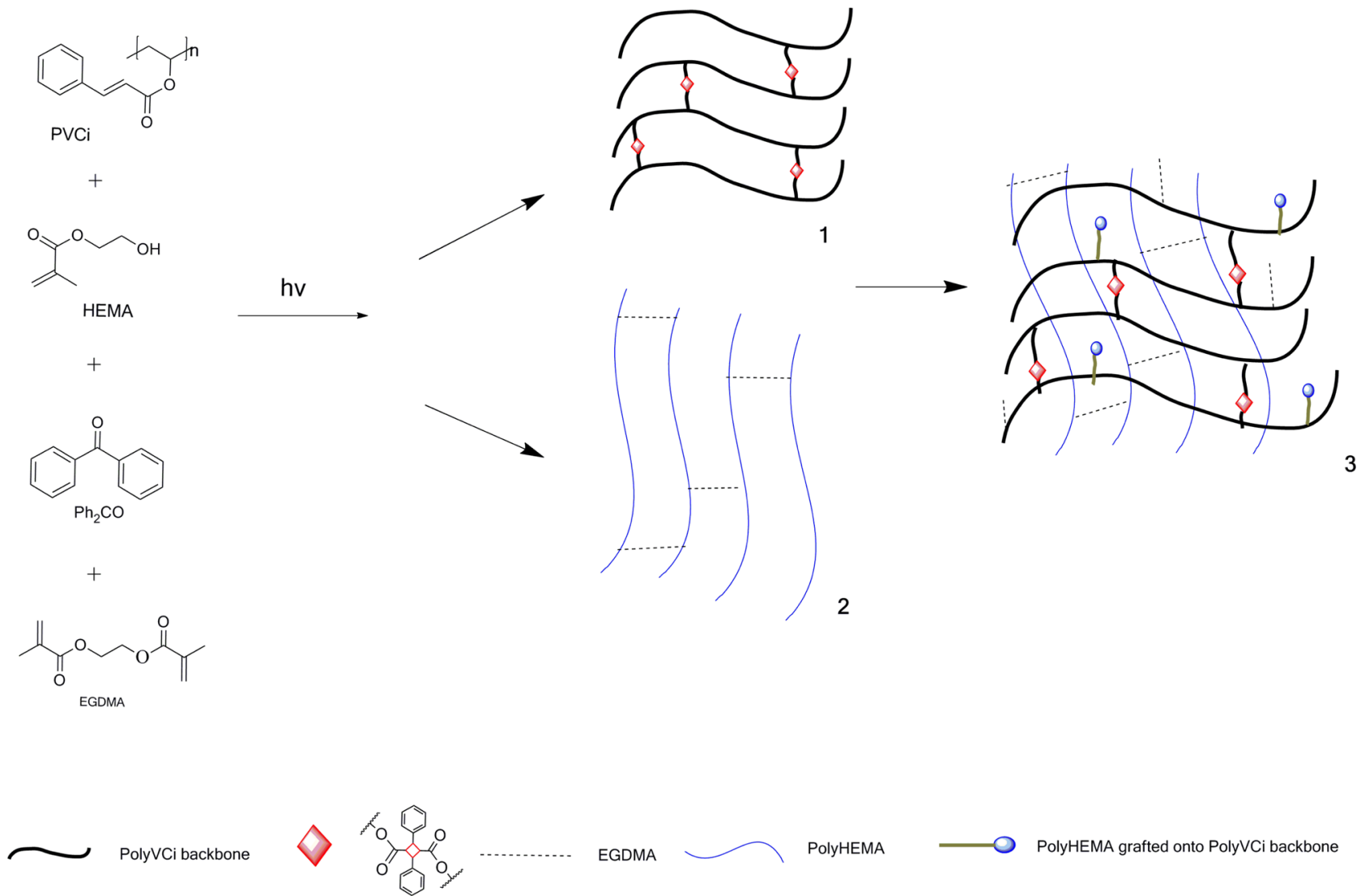

PolyHEMA grafted onto PolyVCi backbone

Fig.1 Schematic representation of ipn-Poly(Vinyl cinnamate-graft-2-hydroxy ethyl methacrylate)- $v$-poly(ethylene glycol dimethacrylate) IPN gel system

the medium forming the EGDMA crosslinked polyHEMA network. Further increase in the $\mathrm{Ph}_{2} \mathrm{CO}$ concentration to $27.4 \mathrm{mM}$ causes a slight decrease in Yield \% to $60.9 \%$. This effect can be an indication of radical-radical combination, which can lead to a decrease in initiator efficiency. Besides, as the initiator concentration increases, the number of short chain homopolymer molecules of HEMA increases, which are easily removed during the washing treatment. Since a decreasing trend was observed above $27.4 \mathrm{mM}$, no higher concentrations of the photoinitiator were tested. Since $13.7 \mathrm{mM} \mathrm{Ph}_{2} \mathrm{CO}$ gave the highest Yield \% value as $67.9 \%$ (sample B), in all other experiments $\mathrm{Ph}_{2} \mathrm{CO}$ was used as $13.7 \mathrm{mM}$.

The effect of EGDMA concentration on the Yield \% is shown in Fig. 2b. The synthesized IPN in the absence of EGDMA, sample $M$ in Table 1, gave $67.4 \%$ Yield value using $41.2 \mathrm{mM}$ HEMA, and $13.7 \mathrm{mM} \mathrm{Ph}_{2} \mathrm{CO}$ after $4 \mathrm{~h} \mathrm{UV}$ irradiation. Sample D prepared under the same conditions as sample $\mathrm{M}$, but by adding $13.2 \mathrm{mM}$ EGDMA to the system resulted in $80.6 \%$ Yield value providing gravimetric evidence for inclusion of EGDMA in the chemical structure. When more EGDMA are added during the IPN synthesis, as exemplified by sample B (26.5 mM EGDMA), and sample
E (52.9 mM EGDMA), a decrease trend in the Yield \% was observed. This behavior may be attributed to more homopolymerization of EGDMA, causing decreasing of crosslinking efficiency of EGDMA towards polyHEMA network. Less Yield \% was achieved as polyEGDMA chains formed are washed away during purification of the product. Less powerful crosslinking efficiency of EGDMA with increasing concentration can be followed from the Gel Content values of the products as well. For M, D, B, and E films the Gel Content does not increase significantly but shows only a slight increase with EGDMA concentration with a tendency to level off as revealed by $61.4,62.2,65.5$, and $67.1 \% \mathrm{Gel}$ Content values respectively for $\mathrm{M}, \mathrm{D}, \mathrm{B}$ and $\mathrm{E}$ films.

Figure 2c indicates that, as the HEMA concentration increases, the Yield\% decreases. This may refer to more uncrosslinked polyHEMA formed, less polyHEMA grafted onto polyVCi backbone or less contribution of EGDMA crosslinked polyHEMA in the network formation. Since uncrosslinked homopolymer chains of polyHEMA can be easily removed through ethanol extraction the Yield\% decreases.

Increasing irradiation time from 4 to 8 and to $12 \mathrm{~h}$, increases the Yield \% from $67.9 \%$ (sample B) to $70.2 \%$ 
Fig. 2 Effect of synthesis conditions on the Yield\% values a $\mathrm{Ph}_{2} \mathrm{CO}, \mathbf{b}$ EGDMA, c HEMA, and $\mathbf{d}$ time

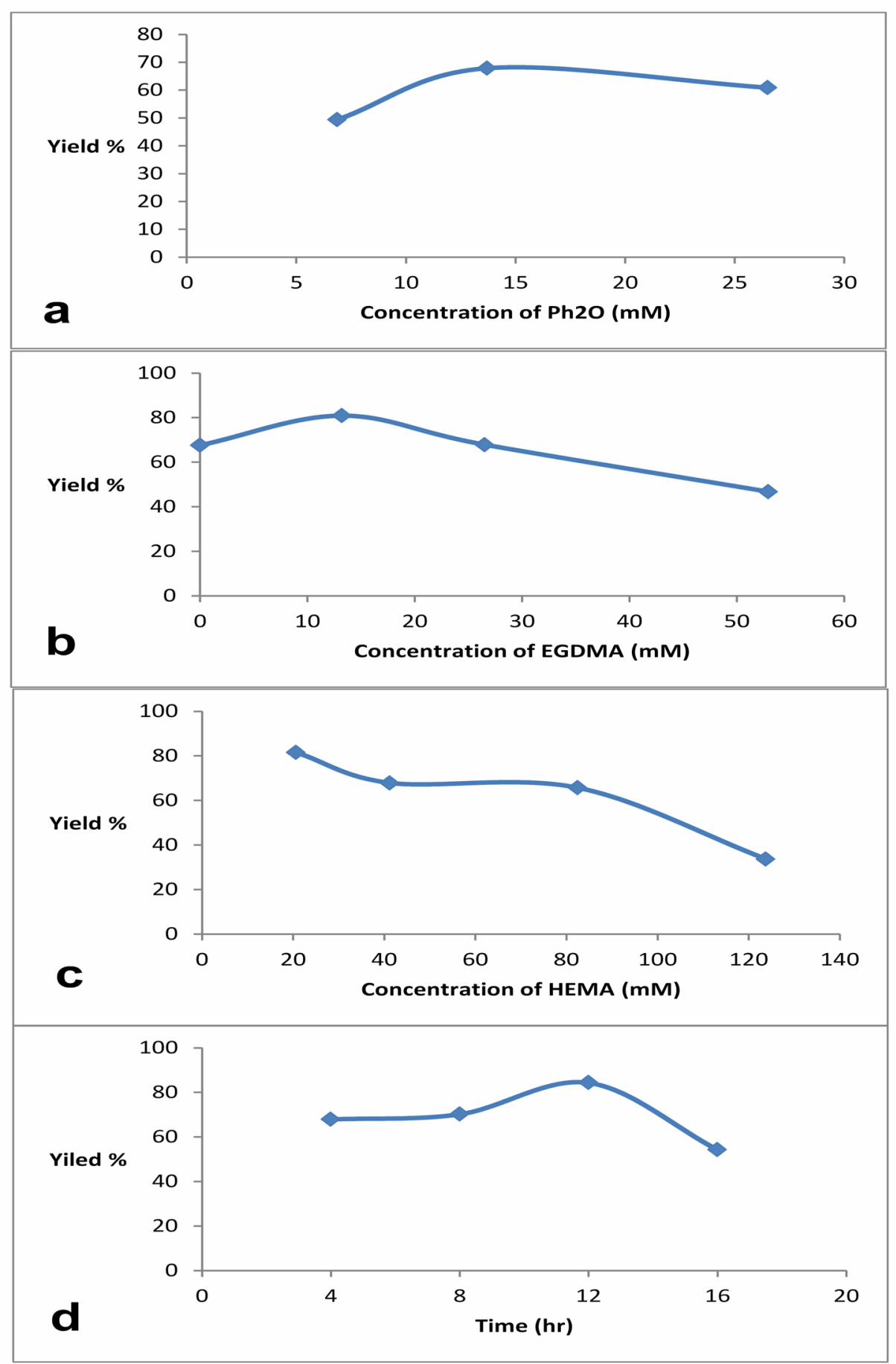

(sample $\mathrm{H}$ ) and to $84.3 \%$ (sample I) respectively. While the THF solvent is evaporated by time, the medium shifts to a bulk environment. As a result, termination reactions predominate over propagation reactions producing a significant increase in the amount of Yield\% (sample I). On the other hand, $16 \mathrm{~h}$ irradiation time (sample $\mathrm{Z}$ ) leads to lower Yield \% value found as $54.2 \%$ (Fig. 2d) due to chain degradation at prolonged irradiation times causing formation of low molecular weight chains that are washed away with ethanol.

The optical pictures of poly VCi, M, B, G, F, and I film samples are shown in Fig. 3. Homogeneous, transparent films of average film thickness $10 \mu \mathrm{m}$ were obtained. 
Fig. 3 The optical pictures of: a PolyVCi, b M film, c B film, d $\mathrm{G}$ film, e F film and $\mathbf{f} \mathrm{I}$ film
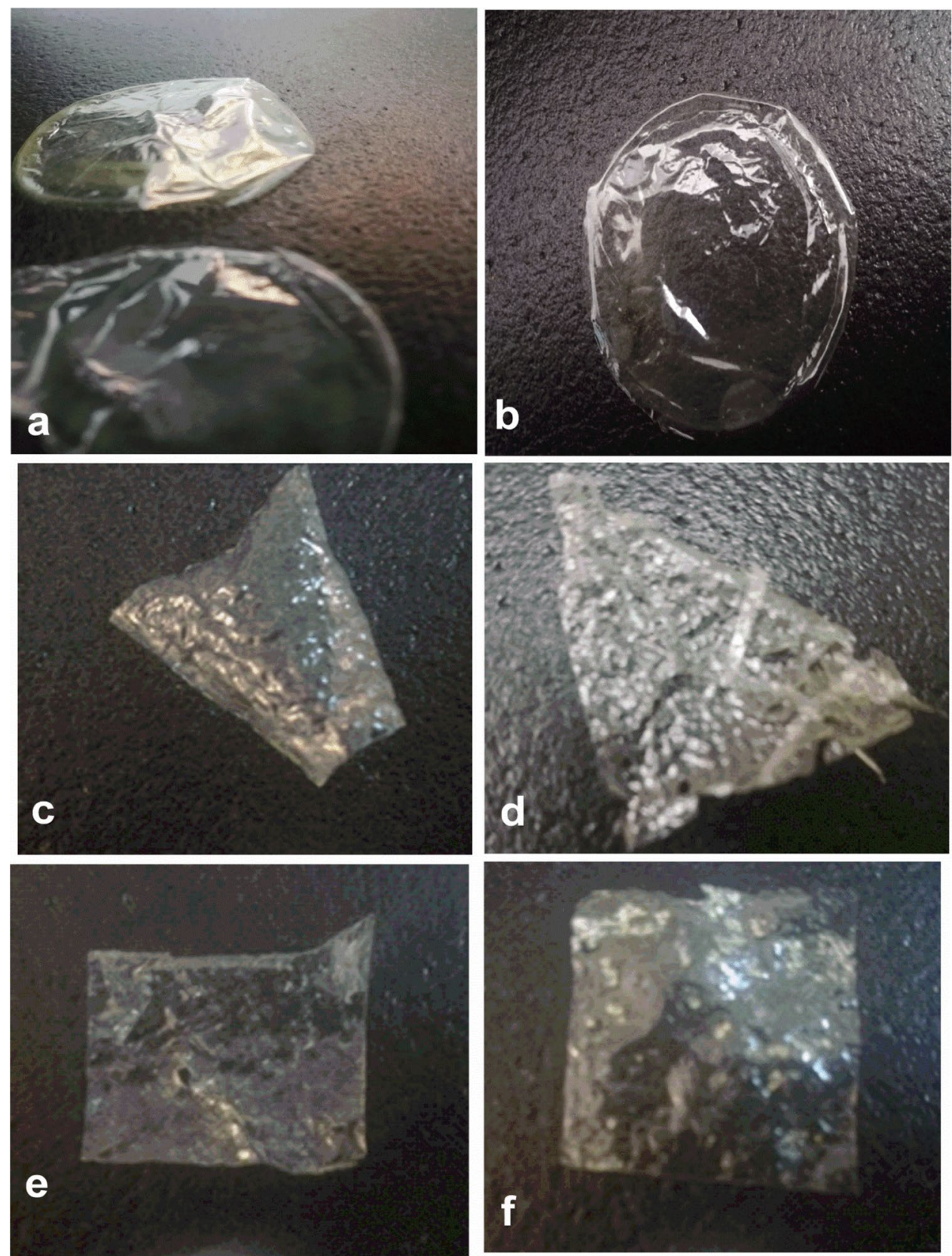

\section{Gel content}

The gel contents of M, B, D, E, and $\mathrm{H}$ films were calculated, and the results reveal that by increasing the initial amount of EGDMA (M, D, B, and E films) the gel content increases only slightly with a tendency to level off as represented by Gel Content values of 61.4, 62.2, 65.5, and $67.1 \%$ respectively. On the other hand, by increasing the UV irradiation (H film) the gel content increases up to $79.4 \%$, which indicates the formation of product of higher crosslinking density in time.

\section{Swelling kinetics}

Swelling characteristics of the films are an important parameter to be evaluated for their application as drug loading and release media. Swelling kinetics of the films was followed in distilled water and in ethanol. The results reported are average values of three measurements for each sample using Microsoft Excel in order to calculate both mean and standard deviation. Figure 4 a shows the swelling behavior of the films in distilled water. All samples reach equilibrium swelling within an hour. Sample M, which is 


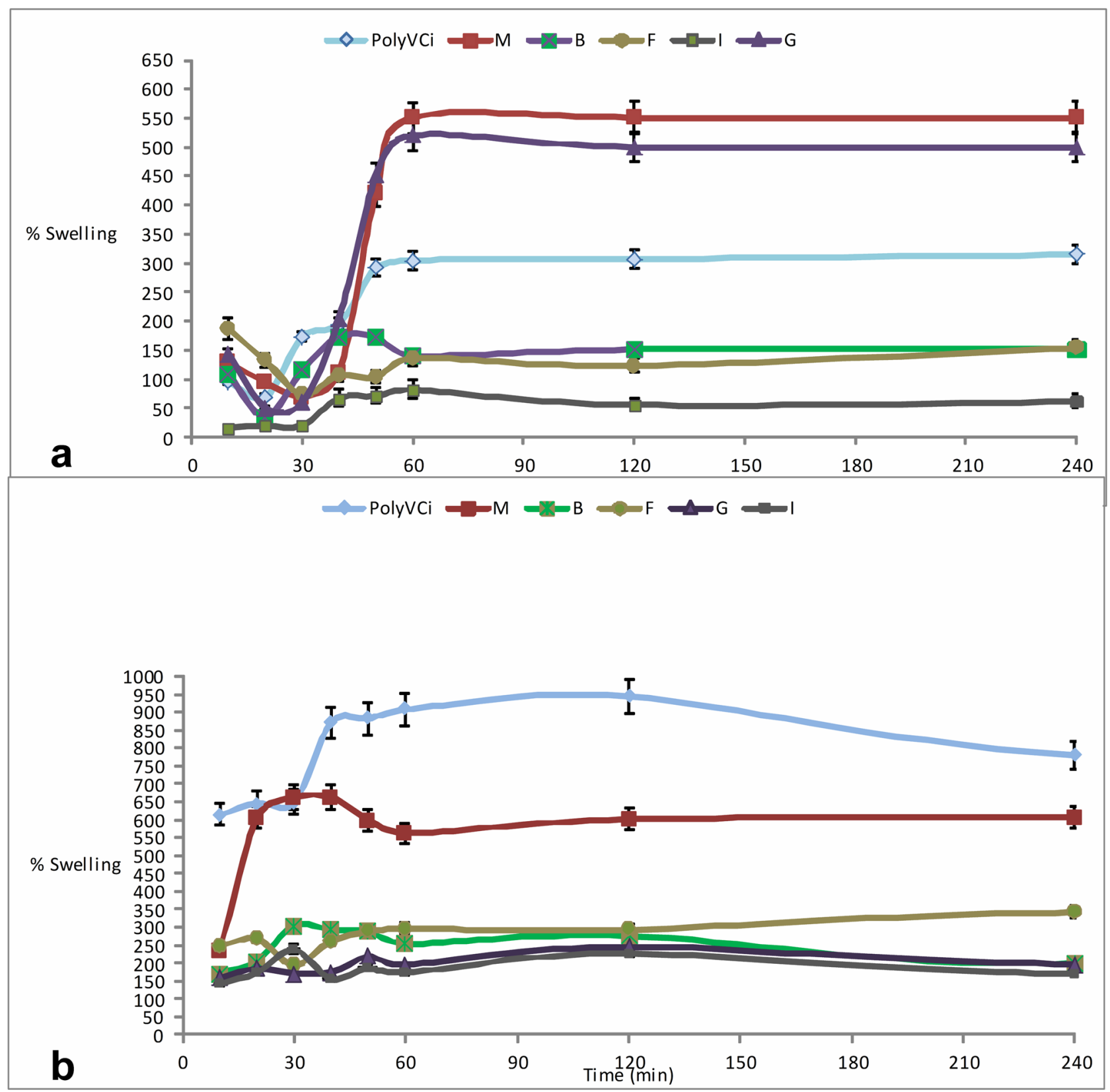

Fig. 4 Swelling behavior of films in a water, $\mathbf{b}$ ethanol. (mean $\pm \mathrm{SD}, n=3)$

synthesized in the absence of EGDMA shows the highest equilibrium swelling value $(550 \%)$. Therefore, it can be concluded that polyVCi backbone gains a hydrophilic nature due to polyHEMA chains incorporated in the polymer matrix. Sample B, on the hand, synthesized under similar conditions with sample $\mathrm{M}$ with the exception that 26.5 M EGDMA is present in the medium possesses an equilibrium swelling capacity of $151 \%$, demonstrating the effect of increased hydrophobicity due to the chemical nature of EGDMA. When sample B (Yield $\%=67.9 \%$ ), and sample $\mathrm{G}($ Yield $\%=65.7 \%)$ are compared to each other, it can be observed that even though they have similar Yield\% values they bear significantly different equilibrium swelling capacities with $151 \%$ and $500 \%$ for sample B and G respectively. This must be due to higher HEMA:EGDMA ratio in sample G ([HEMA]:[EGDMA] $=82.5: 26.5)$ compared to sample B ([HEMA]:[EGDMA] $=41.2: 26.5$ ) resulting in lower crosslinking density and more hydrophilicity due to higher fraction of HEMA in the medium. Sample I (Yield\% $=84.3 \%$ ) that has been exposed to UV irradiation for $12 \mathrm{~h}$, bears smaller equilibrium swelling capacity $(56 \%)$ than the others showing that longer 
exposure to UV light increases the crosslinking density leading to smaller degree of swelling. It is interesting to note that the equilibrium swelling capacity of photocrosslinked poly VCi is unexpectedly high (307\%) and comparable to those of IPN samples even though polyVCi alone is more hydrophobic than polyVCi/polyHEMA/polyEGDMA based IPN samples. This behavior should be due to the macroporous morphology of the polyVCi sample as revealed by SEM analysis discussed below.

Figure $4 \mathrm{~b}$ shows that the maximum $\%$ swelling values in ethanol are higher compared to the values in water. This may be attributed to lower polarity of ethanol than water, which allows more favorable interactions with the hydrophobic polyVCi backbone in addition to favorable interactions of polyHEMA with ethanol. It is interesting to note that polyVCi film alone exhibits the highest swelling capacity in ethanol with $907 \%$ equilibrium swelling capacity. Porous nature of the polyVCi film together with favorable interactions with ethanol should be responsible from this behavior. When sample $\mathrm{F}$ is compared to $\mathrm{B}$ or $\mathrm{G}$, it can be followed from Fig. $4 \mathrm{~b}$ that they bear comparable equilibrium swelling capacity values. This must be due to comparable interaction abilities of the cinnamate and ethyl methacrylate moieties with ethanol. On the other hand, increasing the UV exposure time causes a decrease in the equilibrium $\%$ swelling values, due to higher crosslinking density, the same trend as was observed in water. The equilibrium swelling capacity of sample I prepared under $12 \mathrm{~h} \mathrm{UV}$ exposure reduces to $175 \%$ in ethanol.

\section{FTIR Analysis}

Figure 5a shows the FTIR spectrum of polyVCi film. An absorption band at $1638 \mathrm{~cm}^{-1}$ corresponds to exocyclic $\mathrm{C}=\mathrm{C}$ stretching of cinnamate moieties [25]. The $\mathrm{C}-\mathrm{O}-\mathrm{C}$ stretching vibration of polyVCi exhibits itself at $1164 \mathrm{~cm}^{-1}$. Aromatic $\mathrm{C}-\mathrm{C}$ and $\mathrm{C}-\mathrm{H}$ stretching are observed at 703 and $766 \mathrm{~cm}^{-1}$ respectively. $\mathrm{C}=\mathrm{O}$ stretching of unsaturated ester can be observed at $1710 \mathrm{~cm}^{-1}$ [26].

Two characteristic peaks of polyHEMA (Fig. 5b) are at $3400 \mathrm{~cm}^{-1}$ and $1720 \mathrm{~cm}^{-1}$ corresponding to hydroxyl $(\mathrm{OH})$ and carbonyl $(\mathrm{C}=\mathrm{O})$ stretching vibration bands, respectively [27]. The $\mathrm{C}-\mathrm{O}-\mathrm{C}$ band is observed at $1160 \mathrm{~cm}^{-1}$. The C-O stretching of the primary alcohol of HEMA is observable at $1071 \mathrm{~cm}^{-1}$. In Fig. 5c, the FTIR spectrum of polyVCi/polyHEMA IPN is given. The carbonyl stretching band of the copolymer is observed at $1724 \mathrm{~cm}^{-1}$. The alkene functionality of poly VCi decreases due to the photocrosslinking as can be followed from the smaller $\mathrm{C}=\mathrm{C}$ stretching band at $1638 \mathrm{~cm}^{-1}$ compared to that of poly VCi. The $\mathrm{C}-\mathrm{O}-\mathrm{C}$ stretching band is found at $1160 \mathrm{~cm}^{-1}$. The $\mathrm{C}-\mathrm{O}$ band of the alcohol group of HEMA is at $1076 \mathrm{~cm}^{-1}$. Figure 5d that belongs to sample B, an EGDMA crosslinked polyVCi/polyHEMA sample is characterized

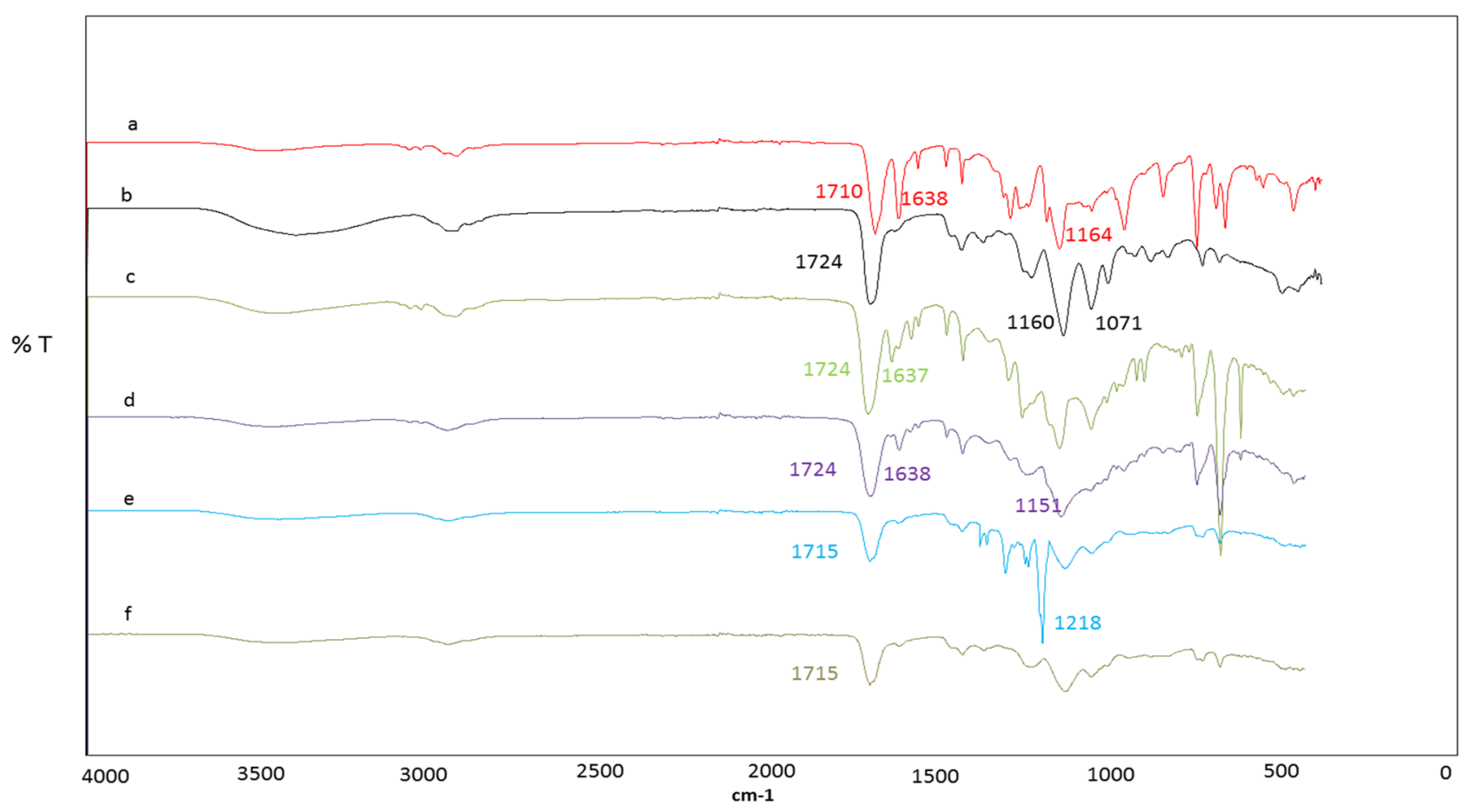

Fig. 5 FTIR spectrum of a PolyVCi b PolyHEMA c sample $\mathrm{M} \mathbf{d}$ sample $\mathrm{B}$ e $\mathrm{FB}_{1}$ and $\mathbf{f} \mathrm{FB}_{1}$ after release 

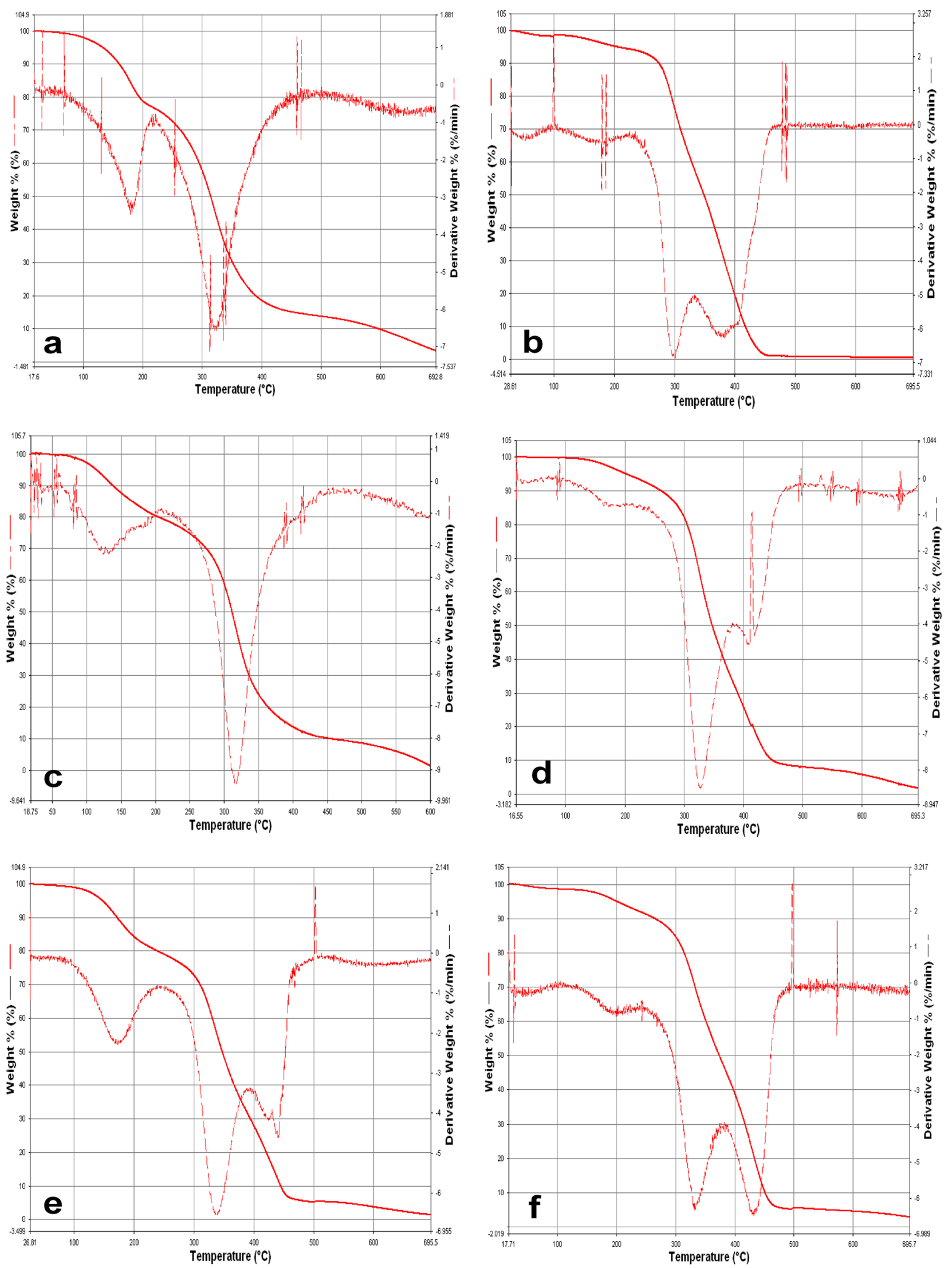

Fig. 6 TGA thermogram of a PolyVCi film; b PolyHEMA; $\mathbf{c}$ M film; d B film; e G film and $\mathbf{f}$ I film 
by a carbonyl band at $1724 \mathrm{~cm}^{-1}$, and an absorption band of poly VCi at $1638 \mathrm{~cm}^{-1}$. Besides these characteristic bands, the overlap of EGDMA, polyVCi and polyHEMA C-O-C bands in the region of $1000-1200 \mathrm{~cm}^{-1}$ is represented by a broader band for $\mathrm{C}-\mathrm{O}-\mathrm{C}$ stretching at $1151 \mathrm{~cm}^{-1}$. Furthermore, the peak intensity of $\mathrm{C}=\mathrm{C}$ stretching vibration at $1638 \mathrm{~cm}^{-1}$ has decreased due to photocrosslinking.

All of these characteristics provide evidence for successful IPN formation between poly VCi and polyHEMA.

FTIR of the drug loaded film (Fig. 5e) shows a characteristic peak at $1218 \mathrm{~cm}^{-1}$ which refers to C-F bond of flurbiprofen. This indicates successful encapsulation of the drug into the IPN. On the other hand, the disappearance of C-F bond in (Fig. 5f) provides data in favor of efficient release of the drug.

\section{Thermal analysis}

Thermal behaviors of the samples have been recorded by thermal gravimetric analysis to provide evidence for thermal stabilities of the samples for future applications. For example, durability to heat sterilization is a requirement for biomedical devices. Figure 6a shows the TGA thermogram of polyVCi. The first decomposition peak is observed at $180{ }^{\circ} \mathrm{C}$ with around $45 \%$ weight loss, while the main mass loss occurs at a temperature around $330{ }^{\circ} \mathrm{C}$. These observations indicate that the cinnamate groups are mainly broken from the main chain at $330{ }^{\circ} \mathrm{C}$, and the detached cinnamates groups are evaporated, resulting in the weight loss [12, 28]. For polyHEMA (Fig. 6b) the decomposition takes place in three stages. In the first stage, around $7 \%$ weight loss occurs at $180^{\circ} \mathrm{C}$. The second stage and third stages where the main weight loss is observed are in the range of $300-400{ }^{\circ} \mathrm{C}$. The first peak is at $300^{\circ} \mathrm{C}$ and refers to the decomposition of $\mathrm{C}-\mathrm{O}$ backbone, while the peak at $370{ }^{\circ} \mathrm{C}$, can be presumed as the decomposition of the methacrylate component.

Figure $6 \mathrm{c}$ shows the thermogram of the film $\mathrm{M}$ that has been prepared in the absence of the crosslinker EGDMA. It has two decomposition peaks. The first one appears at $120{ }^{\circ} \mathrm{C}$ with $30 \%$ weight loss, which refers to water loss. On the other hand, the main decomposition is peak observed at $330{ }^{\circ} \mathrm{C}$, a small amount of polyHEMA incorporated in the polymer matrix does not affect the thermal behavior of polyVCi. For sample B (Fig. 6d) two main decomposition peaks at 330 and $400{ }^{\circ} \mathrm{C}$ are clear evidence for the presence of EGDMA crosslinked polyHEMA in the IPN. The first
Fig. 7 SEM micrographs (X2000) of a PolyVCi, b B film, c $\mathrm{H}$ film, and $\mathbf{d} \mathrm{G}$ film
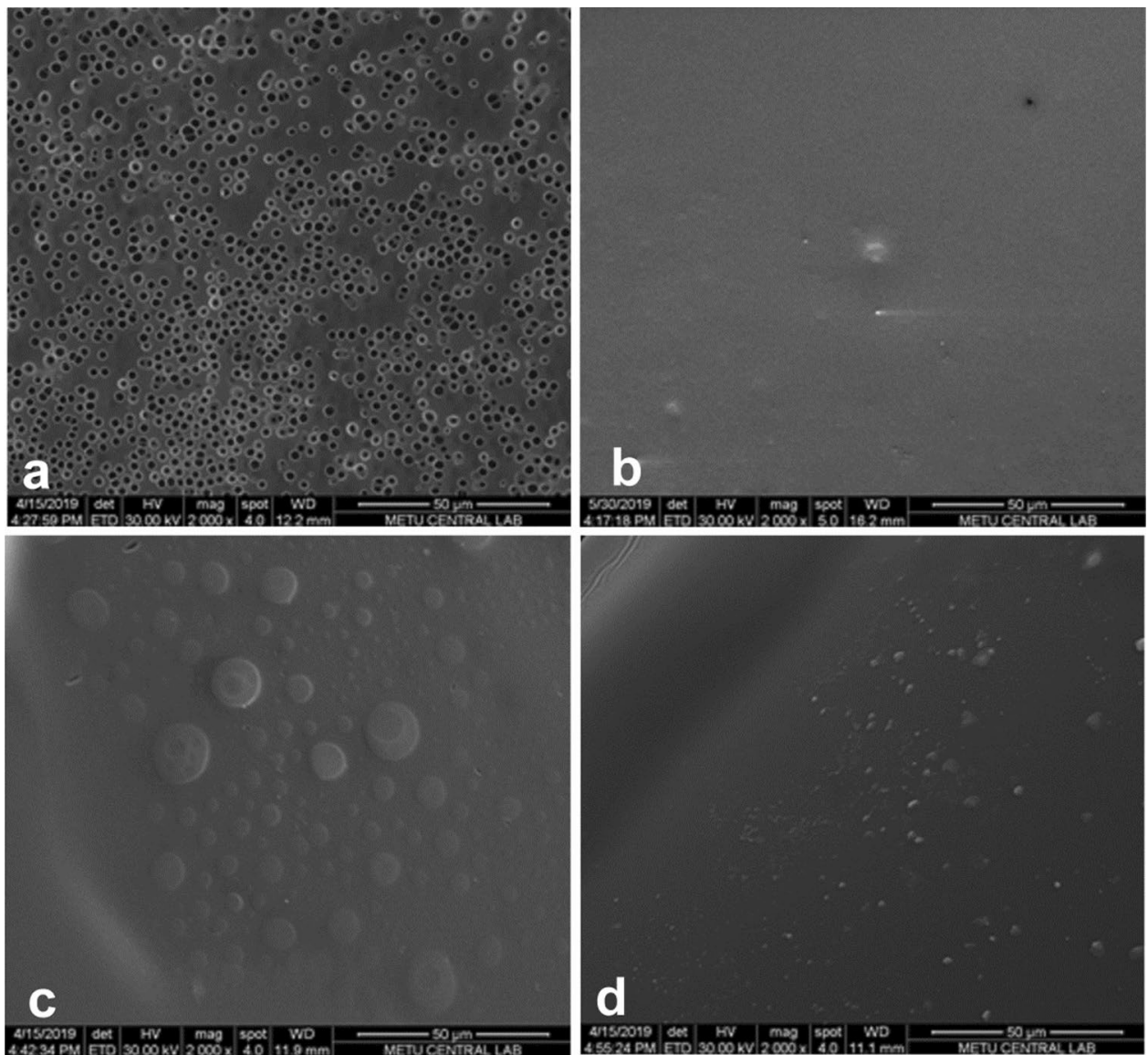
peak at $300{ }^{\circ} \mathrm{C}$ belongs to the decomposition of the poly VCi backbone, while the second decomposition peak that shifts to a higher temperature $\left(400^{\circ} \mathrm{C}\right)$ than that of polyHEMA is a clear evidence for EGDMA crosslinking. For both films $\mathrm{G}$ and I (Fig. 6e and f) similar thermal stability has been observed as for film B.

\section{SEM analysis}

Figure 7 shows the surface morphology of polyVCi film and polyVCi/polyHEMA/polyEGDMA IPN films. The surface of polyVCi film shown in Fig. 7a, exhibits regular pores. The pore size as measured from the SEM picture is of the order of 1-2 microns. The formation of pores has been attributed to the evaporation of THF solvent during the photopolymerization, in other words THF acts as porogen. The surfaces of the IPN films exhibit heterogeneity on a continuous phase which reveals formation of interpenetrating network of two crosslinked polymers with different chemical nature. (Fig. 7b-d). When films B (4 h UV irradiation) and $\mathrm{H}(8 \mathrm{~h}$ UV irradiation) are compared to each other, the effect of more UV irradiation on the morphology can be followed. Film $\mathrm{H}$ exhibits larger islands on the continuous phase providing evidence for higher crosslinking of polyHEMA in time via EGDMA incorporation into the system. Film G, on the other hand, bears a more homogenous surface that can be attributed to less crosslinking due to higher HEMA concentration in the polymerization in the medium compared to samples $\mathrm{B}$ and $\mathrm{H}$.

\section{Contact angle}

Contact angle is a useful tool to estimate the hydrophilicity of the polymer films. The data presented below provide evidence for surface modification of poly VCi via hybridization with polyHEMA. It also gives a clue on the expected compatibility of the film with other hydrophilic surfaces, biomolecules or drugs. Figure 8 shows that the surface of the IPN formed is more hydrophilic than that of polyVCi. The contact angle of IPN film decreases from $77.23^{\circ}$ to $64.11^{\circ}$ (sample B) (Fig. 8a and b). Film I (Fig. 8c) shows more hydrophilicity than polyVCi, but less than that of B film with a contact angle of $70^{\circ}$ due to more hydrophobicity imparted by more EGDMA crosslinking in time (12 h).

\section{Flurbiprofen loading and release}

Flurbiprofen (Fig. 9) was loaded into polyVCi/polyHEMA/ polyEGDMA matrix during IPN formation. Two film samples loaded with flurbiprofen $\mathrm{FB}_{1}$ and $\mathrm{FB}_{2}$ were used in the release study. The amount of flurbiprofen encapsulated into the film was assumed to be the same as the amount of drug released from the loaded films at time infinity $\left(\mathrm{M}_{\infty}\right)$. These

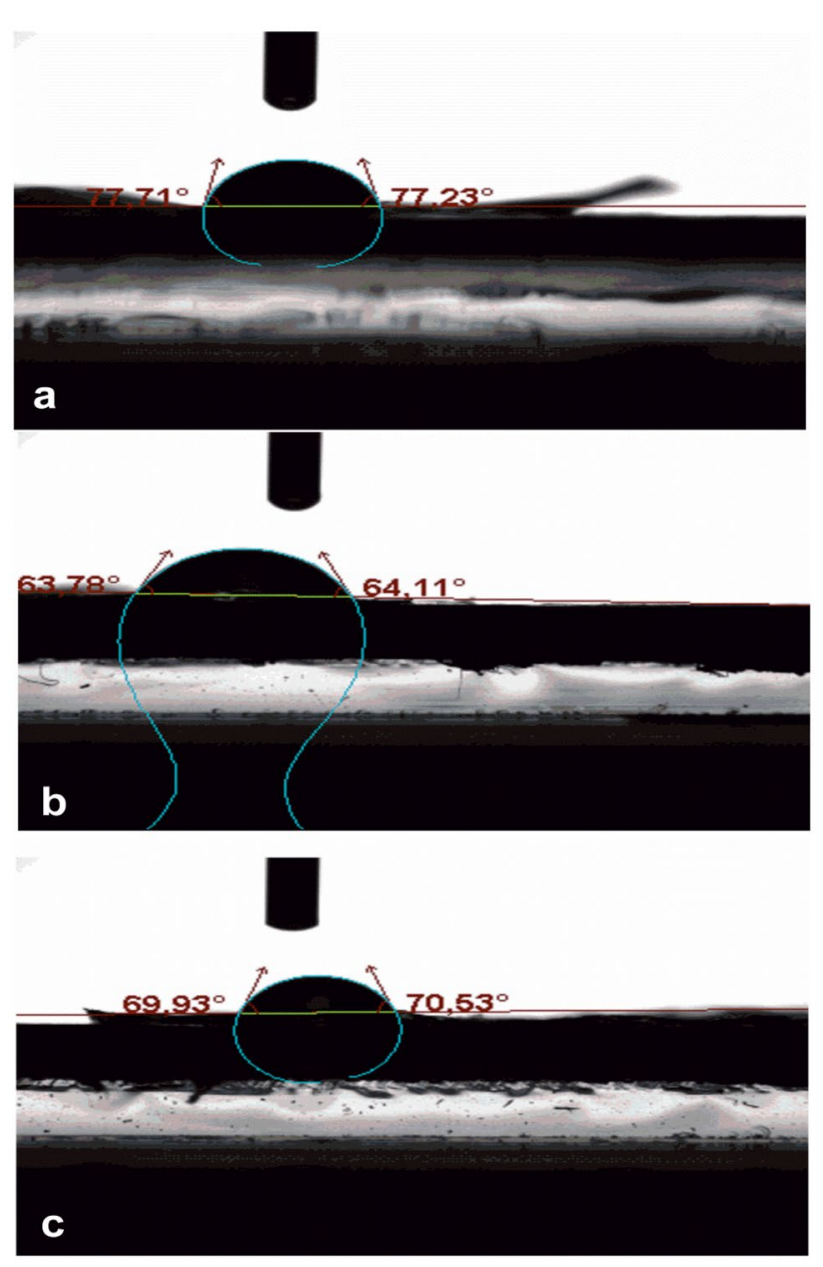

Fig. 8 Contact angle of a PolyVCi, b B film, and $\mathbf{c}$ I film

values are $36.5 \mathrm{mg}$ and $43.6 \mathrm{mg} \mathrm{FB}{ }_{1}$ and $\mathrm{FB}_{2}$ respectively. Accordingly, the encapsulation efficiency of $\mathrm{FB}_{1}$ and $\mathrm{FB}_{2}$ has been calculated as $73.0 \%$ and $43.6 \%$ respectively.

As can be observed from Fig. 10a, flurbiprofen release from $\mathrm{FB}_{1}$ shows a two-step release profile with an initial pulse within first $5 \mathrm{~h}$ demonstrating 32\% cumulative release. This is followed by no release for a period of $15 \mathrm{~h}$ that can be identified as lag time period. After the lag time period, the drug is released with a second pulse, which is a release period that begins at $20 \mathrm{~h}$ and is completed at $35 \mathrm{~h}$. A similar behavior has been observed for $\mathrm{FB}_{2}$ film, except that the total release during the first release stage, within the first $5 \mathrm{~h}$, is $22 \%$ (Fig. 10b). In both cases, it is clear that a time controlled flurbiprofen release system is obtained by loading the drug into poly VCi/polyHEMA/polyEGDMA films. Two factors can be considered to explain the lag time behavior. These are the nature of the drug-matrix interaction and the morphology of the polyVCi/polyHEMA/polyEGDMA matrix. Carbonyl functionalities available both on polyHEMA and poly VCi interact with flurbiprofen molecule via dipole-dipole interactions. Secondary interactions such 

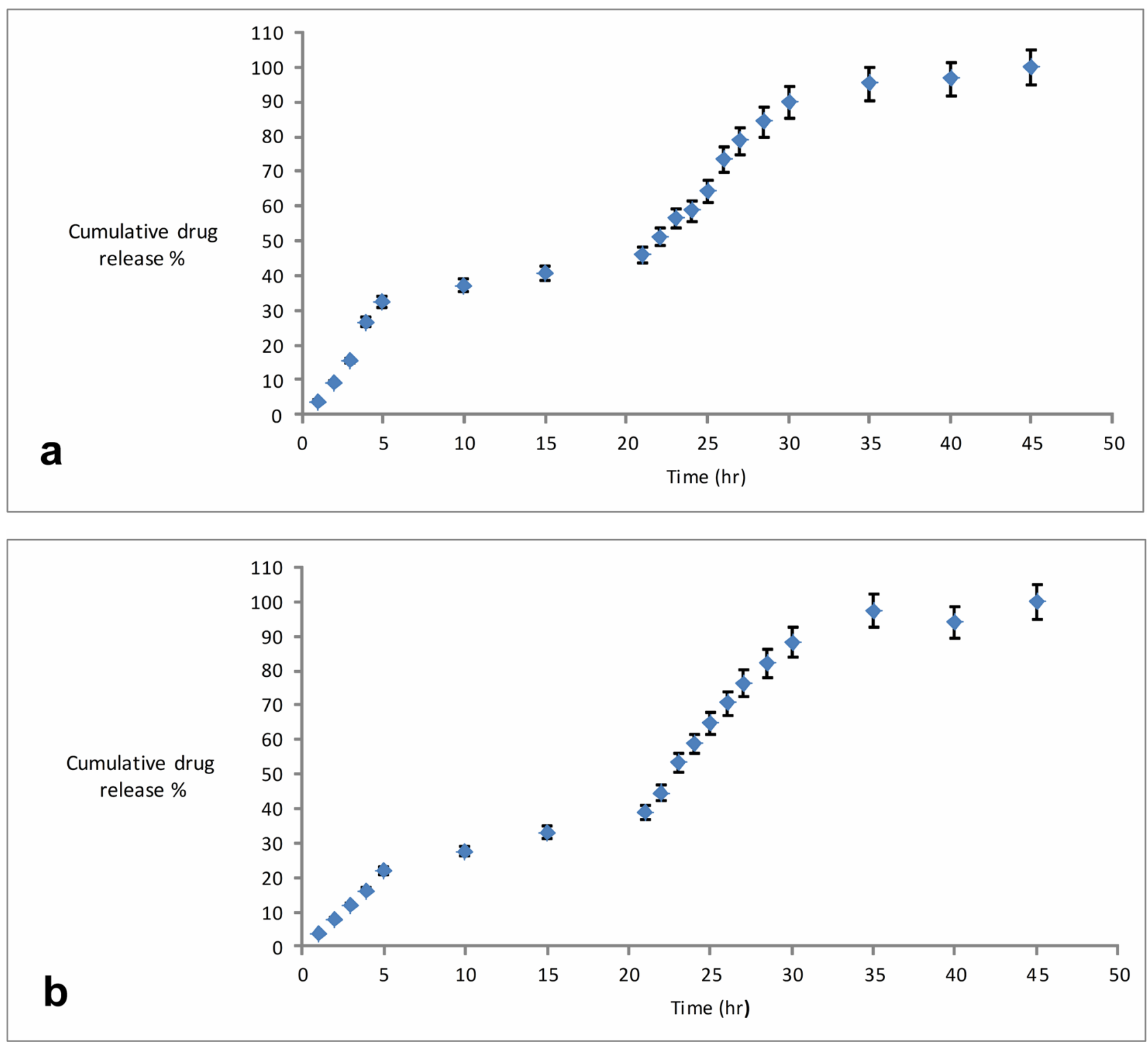

Fig. 9 Flurbiprofen release profile from $\mathbf{a} \mathrm{FB}_{1}$, b FB $\mathrm{Films}_{2}$ (mean $\pm \mathrm{SD}, n=3$ )

as dispersion forces and dipole-dipole interactions are also available between benzene rings that exist in both poly VCi and flurbiprofen. Flurbiprofen, and polyHEMA component of the matrix may interact via hydrogen bonding interaction between the - $\mathrm{OH}$ groups available on both molecules or via strong dipole-dipole interaction between the fluorine atom and the hydroxyl group. So, it may be concluded that there are stronger favorable interactions between polyHEMA component of the copolymer than between polyVCi and flurbiprofen. Furthermore, polyVCi/polyHEMA/polyEGDMA films show two phase morphology as can be observed in the SEM pictures given in Fig. 7. Two types of crosslinked regions are available in the matrix: the poly VCi network and EGDMA crosslinked polyHEMA network. The islands embedded in the continuous poly $\mathrm{VCi}$ matrix have been attributed to the EGDMA crosslinked polyHEMA regions within the IPN matrix. Flurbiprofen is distributed randomly in the IPN matrix during the photo encapsulation process. Hence, diffusion rate of the flurbiprofen molecule through these two different regions with different chemical nature and crosslinking density should be different resulting in the two-stage release behavior.

To understand the mechanism and kinetics of drug release, the results obtained were studied for two periods of release separately. The first one was from (time $0-5) \mathrm{h}$ and denoted by PI, while the second period, PII, was used for the second release (20-30) h. The data were fit into different kinetic equations such as: zero order model (Eq. 1) 


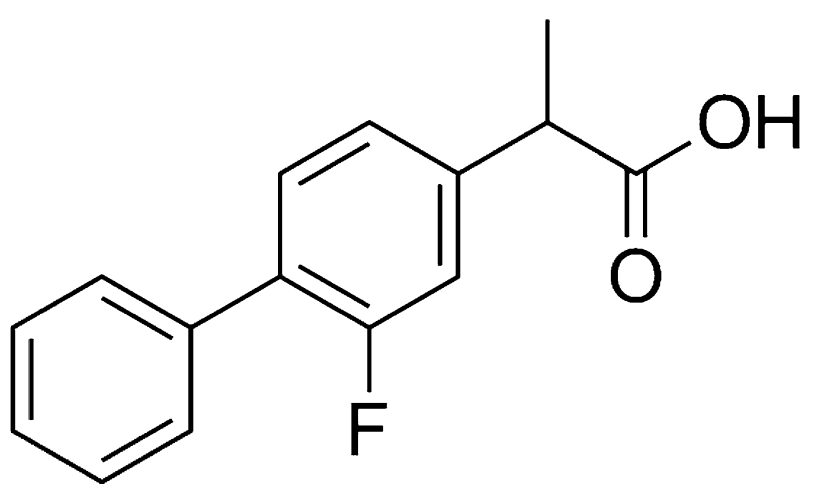

Fig. 10 Chemical structure of Flurbiprofen

(plotting cumulative \% drug released versus time), first order (Eq. 2) (plotting log cumulative \% drug remained versus time), Higuchi (Eq. 3) (plotting cumulative \% released versus $\sqrt{ }$ time), and Korsmeyer Peppas (Eq. 4) (plotting log of the drug dispersed in the glassy polymer matrix creating a swelling controlled system. As the solvent (ethanol) penetrates the matrix, the polymer swells and gains the rubbery state. Hence, the drug will be able to diffuse through the matrix. Although diffusion in rubbery systems at equilibrium is generally Fickian, diffusion in a rubbery state which is not at equilibrium may be Fickian or non-Fickian due to the continuous swelling. In sequence, these macromolecular relaxations, and the concentration of ethanol in the polymer matrix, control the release behavior of flurbiprofen.

The drug release of glassy polymers can be express by Korsmeyer-Peppas equation (Eq. 4). Herein, the mechanisms of drug release are characterized using the release exponent ( $\mathrm{n}$ value). The diffusion with Fickian is achieved when $n=0.5$; when the $n$ value lies in the range $0.5<n<1$ that indicates an anomalous (non-Fickian) diffusion release model. An $n$ value of 1 corresponds to case II transport, and $n>1$ indicates a super case II transport relaxational
Table 2 Drug release kinetic data

\begin{tabular}{llllll}
\hline & $\mathrm{FB}_{1}$ & & & $\mathrm{FB}_{2}$ & \\
\cline { 2 - 3 } Zero order & Period I $(0-5 \mathrm{~h})$ & Period II $(20-30 \mathrm{~h})$ & & Period I $(0-5 \mathrm{~h})$ & Period II $(20-30 \mathrm{~h})$ \\
\hline First order & $\mathrm{R}^{2}=0.8867$ & $\mathrm{R}^{2}=0.9456$ & & $\mathrm{R}^{2}=1$ & $\mathrm{R}^{2}=1$ \\
Higuchi & $\mathrm{R}^{2}=0.8568$ & $\mathrm{R}^{2}=0.8118$ & & $\mathrm{R}^{2}=0.9997$ & $\mathrm{R}^{2}=0.9994$ \\
Korsmeyer Peppas & $\mathrm{R}^{2}=0.8087$ & $\mathrm{R}^{2}=0.9356$ & & $\mathrm{R}^{2}=0.9129$ & $\mathrm{R}^{2}=0.9993$ \\
& $\mathrm{R}^{2}=0.7508$ & $\mathrm{R}^{2}=1$ & & $\mathrm{R}^{2}=0.9089$ & $\mathrm{R}^{2}=1$ \\
& $n=1.42$ & $n=1.12$ & $n=1.28$ & $n=1.0$ \\
\hline
\end{tabular}

cumulative \% drug released versus log time, where the slope represents the $n$ value). The kinetic model that best fits the dissolution data was estimated by comparing the correlation coefficient $\left(R^{2}\right)$ values obtained in various models. Flurbiprofen was dissolved in the polymer solution, and then the THF solvent was evaporated after UV irradiation leaving release [29]. The case II transport represents the flurbiprofen release when ethanol moves with a constant velocity toward the glassy matrix, while in long time of releasing periods, super case II transport mechanism may be achieved for some systems once a continuous swelling behavior of the relaxing polymer occur [30].

Table 3 A Comparison of Flurbiprofen Release Systems

\begin{tabular}{|c|c|c|c|}
\hline System & Drug Loading & Release Profile & Reference \\
\hline $\begin{array}{l}\text { Poly(methyl methacrylate)/ } \beta \text {-tricalcium phosphate } \\
\text { biocomposite }\end{array}$ & $26 \%$ & $50 \%$ release within $4 \mathrm{~h}$ (ethanol) & {$[32]$} \\
\hline Starch/2-isocyanoethyl methacrylate & $4.7 \mathrm{mg} / \mathrm{mg}$ & $100 \%$ release within $72 \mathrm{~h}(0.9 \% \mathrm{NaCl}$ solution $37 \mathrm{C})$ & {$[33]$} \\
\hline $\begin{array}{l}\text { Copolymers of acrylic acid and methyl methacrylate } \\
(2.5: 7.5 \text { and } 2: 8)\end{array}$ & $5.89 \%$ & $\begin{array}{l}\text { The microspheres released } \\
43 \text { and } 36 \% \text { drug at } \mathrm{pH} 6.8 \text { in } 2 \mathrm{~h} \text { and } 99 \text { and } 96 \% \text { at } \mathrm{pH} \\
7.4 \\
\text { in next } 3-4 \mathrm{~h} \text {. (phosphate buffer) }\end{array}$ & {$[11]$} \\
\hline $\begin{array}{l}\text { Poly(hydroxyethyl methacrylate-co-methacrylic acid) } \\
\text { Cross Linked Polymeric Network }\end{array}$ & $69.74 \mathrm{mg} / \mathrm{g}$ & $\begin{array}{l}16.26 \% \text { drug was released at } \mathrm{pH} 1.2 \text { while } 100 \% \text { drug } \\
\text { release was observed at } \mathrm{pH} 7.4 \text { after } 24 \text { h of in-vitro } \\
\text { release study. (phosphate buffer) }\end{array}$ & {$[34]$} \\
\hline PolyVCi/polyHEMA/polyEGDMA & $73 \%\left(\mathrm{FB}_{1}\right)$ & $\begin{array}{l}\text { flurbiprofen release from } \mathrm{FB}_{1} \text { shows a two-step release } \\
\text { profile with an initial pulse within first } 5 \mathrm{~h} \text { with } 32 \% \\
\text { cumulative release, followed by no release for a period } \\
\text { of } 15 \mathrm{~h} \text {, then a second release period that begins at } 20 \mathrm{~h} \\
\text { and is completed at } 35 \mathrm{~h} \text {.(ethanol) }\end{array}$ & This work \\
\hline
\end{tabular}


In flurbiprofen loaded polyVCi/polyHEMA/polyEGDMA films studied in this work, it has been established that these systems obey zero order release kinetics, which is an important advantage. Zero-order release is the ideal in controlled drug release and has an advantage of delivering drugs at a constant rate. Zero-order has been reported not to be familiar with matrix systems, due to time-dependent changes in drug depleted matrix surface area and diffusional path length [31].

Table 2 shows that the most probable release kinetics for the flurbiprofen loaded films $\left(\mathrm{FB}_{1}\right.$, and $\left.\mathrm{FB}_{2}\right)$ in both periods (PI, and PII), are zero order since a higher " $\mathrm{R}$ " " values were obtained. The zero-order rate describes systems where drug release rate is independent of its concentration. This mechanism is confirmed by its Ritger-Peppas " $n$ " value (1.00 to 1.42), which indicates super case II release mechanism.

A comparison of the release behavior of flurbiprofen from polyVCi/polyHEMA/polyEGDMA IPN system to other polymethacrylate bearing matrices is illustrated in Table 3. A summary of the release kinetics parameters of some examples are given in Table 3. Our IPN system provides a higher loading $\%$ of the drug $(73.0 \%)$ within the synthesized matrix, and more versatile time-controlled release with two periods; the first gives $32 \%$ within the first $5 \mathrm{~h}$, and the second one begins at $20 \mathrm{~h}$ and it is completed at $35 \mathrm{~h}$, where in the period of 5-20 h, lag time was achieved. No poly VCi/flurbiprofen system could be found in the literature for comparison.

\section{Conclusions}

Photoinitiated simultaneous IPN formation in between poly$\mathrm{VCi}$ and polyHEMA in the absence or presence of EGDMA was successfully achieved and optimized. The IPN films are homogenous at the macroscopic level and are transparent film material. However, they exhibit heterogenicity at the microscopic level due to the formation of a dual network. Hydrophilicity of the IPN films increases with increasing amount of polyHEMA in the medium as demonstrated by contact angle measurements and equilibrium swelling capacities in water and in ethanol. The films are thermally stable up to around $300{ }^{\circ} \mathrm{C}$, as revealed by TGA. Successful photo-encapsulation of flurbiprofen into the film matrix was achieved. The IPN films proved to be suitable release matrixes for flurbiprofen demonstrating two stage release behavior. As a result, IPN films are promising devices for a time-controlled release of flurbiprofen. In vitro biocompatibility tests will form the second stage of this study for further biological characterization of the system.

Acknowledgment The authors gratefully acknowledge the funding of this work by Eastern Mediterranean University (BAP-C-04-18-02).

\section{References}

1. Tallapaka SH, Karuturi VK, Sotthivirat S, Vetro JA (2015) Controlled Drug Delivery. Drug Deliv 1st Ed Burlingt Jones Bartlet Learn 108-128

2. Ferreira P, Coelho JFJ, Almeida JF, Gil MH (2011) Photocrosslinkable polymers for biomedical applications. Biomed Eng Challenges 1:55-74

3. Singh A, Dubey H, Shukla I, Singh DP (2012) Pulsatile drug delivery system: An approach of medication according to circadian rhythm. J Appl Pharm Sci 2:166-176

4. Siepmann J, Siepmann F (2008) The modified-release drug delivery landscape: academic viewpoint. Modif release drug Deliv Technol Second ed Inf Healthc USA, Inc, New York 17-34

5. Alshhab A, Yilmaz E (2020) Sodium alginate/poly (4-vinylpyridine) polyelectrolyte multilayer films: Preparation, characterization and ciprofloxacin $\mathrm{HCl}$ release. Int J Biol Macromol 147:809-820

6. Bhardwaj V, Harit G, Kumar S (2012) Interpenetrating polymer network (IPN): novel approach in drug delivery. Int J Drug Dev Res 4:41-54

7. Wu W, Wang D, Lian Y (2013) Controlled release of bovine serum albumin from stimuli-sensitive silk sericin based interpenetrating polymer network hydrogels. Polym Int 62:1257-1262

8. Kulkarni RV, Boppana R, Mohan GK et al (2012) pH-responsive interpenetrating network hydrogel beads of poly (acrylamide)-gcarrageenan and sodium alginate for intestinal targeted drug delivery: Synthesis, in vitro and in vivo evaluation. J Colloid Interface Sci 367:509-517

9. Dragan ES, Cocarta AI (2016) Smart macroporous IPN hydrogels responsive to $\mathrm{pH}$, temperature, and ionic strength: synthesis, characterization, and evaluation of controlled release of drugs. ACS Appl Mater Interfaces 8:12018-12030

10. Donnelly L, Hardy JG, Gorman SP et al (2017) Photochemically Controlled Drug Dosing from a Polymeric Scaffold. Pharm Res 34:1469-1476. https://doi.org/10.1007/s11095-017-2164-9

11. Vijay S, Sati OP, Majumdar DK (2011) Acrylic acid-methyl methacrylate (2.5: 7.5/2: 8) enteric copolymer for colon targeted drug delivery. J Mater Sci Mater Med 22:125-135

12. Du H, Zhang J (2012) The synthesis of poly(vinyl cinnamates) with light-induced shape fixity properties. Sensors Actuators, A Phys 179:114-120. https://doi.org/10.1016/j.sna.2012.02.001

13. Wang MH, Kim JC (2015) Nanogels Composed of Cinnamoyl Alginate and Cinnamoyl Pluronic F127. J Dispers Sci Technol 36:377-383. https://doi.org/10.1080/01932691.2014.913491

14. Esen H, Küsefoğlu S, Wool R (2007) Photolytic and free-radical polymerization of monomethyl maleate esters of epoxidized plant oil triglycerides. J Appl Polym Sci 103:626-633. https:// doi.org/10.1002/app.25155

15. Iqbal D, Samiullah MH (2013) Photo-responsive shape-memory and shape-changing liquid-crystal polymer networks. Materials (Basel) 6:116-142

16. Ali AH, Srinivasan KSV (2002) Synthesis, characterization, and studies on the solid-state crosslinking of functionalized vinyl cinnamate polymers. J Appl Polym Sci 67:441-448. https:// doi.org/10.1002/(sici)1097-4628(19980118)67:3\%3c441:: aid-app6\%3e3.0.co;2-m

17. Sheng C, Wenting B, Shijian T, Yuechuan W (2008) Electrochromic Behaviors of Poly (3-n-octyloxythiophene ). Polymer (Guildf) 108:900-903. https://doi.org/10.1002/app

18. Zhang Y, Lam YM, Tan WS (2005) Poly(ethylene oxide)poly(propylene oxide)-poly(ethylene oxide)-g-poly (vinylpyrrolidone): Association behavior in aqueous solution and interaction with anionic surfactants. J Colloid Interface Sci 285:74-79. https://doi.org/10.1016/j.jcis.2004.12.033 
19. Singh U, Davis F, Mohan S, Mitchell G (2013) Electro-active nanofibres electrospun from blends of poly-vinyl cinnamate and a cholesteric liquid crystalline silicone polymer. J Mater Sci 48:7613-7619

20. Hsu W-P, Chiou M-S, Li H-Y (2012) Miscibility of mixed stereoregular PMMA/PVCN monolayers at the air/water interface. J Appl Polym Sci 124:333-341

21. Ramesan MT, Jayakrishnan P (2017) Role of nickel oxide nanoparticles on magnetic, thermal and temperature dependent electrical conductivity of novel poly (vinyl cinnamate) based nanocomposites: applicability of different conductivity models. J Inorg Organomet Polym Mater 27:143-153

22. Su G, Zhou T, Zhang Y et al (2016) Microdynamics mechanism of D $2 \mathrm{O}$ absorption of the poly(2-hydroxyethyl methacrylate)based contact lens hydrogel studied by two-dimensional correlation ATR-FTIR spectroscopy. Soft Matter 12:1145-1157. https:// doi.org/10.1039/c5sm02542g

23. Kukolevska OS, Gerashchenko II, Borysenko MV et al (2017) Synthesis and Examination of Nanocomposites Based on Poly(2hydroxyethyl methacrylate) for Medicinal Use. Nanoscale Res Lett 12:133. https://doi.org/10.1186/s11671-017-1881-7

24. Jafari S, Soleimani M, Salehi R (2018) Nanotechnology-based combinational drug delivery systems for breast cancer treatment. Int J Polym Mater Polym Biomater 68:859-869. https://doi. org/10.1080/00914037.2018.1517348

25. Petruczok CD, Armagan E, Ince GO, Gleason KK (2014) Initiated chemical vapor deposition and light-responsive cross-linking of poly(vinyl cinnamate) thin films. Macromol Rapid Commun 35:1345-1350. https://doi.org/10.1002/marc.201400130

26. Ni Y, Zheng S (2004) A novel photocrosslinkable polyhedral oligomeric silsesquioxane and its nanocomposites with poly(vinyl cinnamate). Chem Mater 16:5141-5148. https://doi.org/10.1021/ $\mathrm{cm} 049463 \mathrm{k}$
27. Kodama Y, Barsbay M, Güven O (2014) Poly(2-hydroxyethyl methacrylate) (PHEMA) grafted polyethylene/polypropylene (PE/ $\mathrm{PP})$ nonwoven fabric by $\gamma$-initiation: Synthesis, characterization and benefits of RAFT mediation. Radiat Phys Chem 105:31-38. https://doi.org/10.1016/j.radphyschem.2014.05.023

28. Kim H-T, Park J-K (1998) Thermal degradation of poly(vinyl cinnamate)

29. Ofokansi KC, Adikwu MU, Okore VC (2007) Preparation and evaluation of mucin-gelatin mucoadhesive microspheres for rectal delivery of ceftriaxone sodium. Drug Dev Ind Pharm 33:691-700. https://doi.org/10.1080/03639040701360876

30. Langer RS, Peppas NA (1981) Present and future applications of biomaterials in controlled drug delivery systems. Biomaterials 2:201-214

31. Obitte NC, Chukwu A, Onyishi IV (2010) The use of a pHdependent and Non $\mathrm{pH}$-dependent natural hydrophobic biopolymer (Landolphia owariensis latex) as capsule coating agents in in vitro controlled release of metronidazole for possible colon targeted delivery. Int J Appl Res Nat Prod 3:1-17

32. Ngo TT, Blair S, Kuwahara K et al (2018) Drug impregnation for laser sintered poly (methyl methacrylate) biocomposites using supercritical carbon dioxide. J Supercrit Fluids 136:29-36

33. Vieira AP, Ferreira P, Coelho JFJ, Gil MH (2008) Photocrosslinkable starch-based polymers for ophthalmologic drug delivery. Int J Biol Macromol 43:325-332

34. Rashid H, Ahmad M, Minhas MU, et al (2015) Synthesis and Characterization of Poly (hydroxyethyl methacrylate-comethacrylic acid) Cross Linked Polymeric Network for the Delivery of Analgesic Agent. J Chem Soc Pakistan 37

Publisher's Note Springer Nature remains neutral with regard to jurisdictional claims in published maps and institutional affiliations. 